\title{
EDITORIAL
}

\section{Sabiendo lo que hay que saber en Ciencias de la Madera: revalorizado en la sociedad del conocimiento}

\author{
Rubén A. ANANIAS \\ Director-Editor
}

La creación de conocimiento cambió el paradigma de una economía basada en inversiones en capital y trabajo a una economía basada en inversiones en nuevo conocimiento, para mejorar la calidad del capital humano y físico. Así, el nuevo conocimiento se transformó en el motor de desarrollo del país, por lo tanto la formación del capital humano se ha vuelto más relevante en la economía. El tránsito de la economía a la sociedad del conocimiento, esta siendo sustentado por el uso intensivo del nuevo conocimiento, que atraviesa las múltiples actividades productivas del país, aprovechando la ciencia para ir alcanzando ritmos altos de productividad basada en conocimientos.

La sociedad del conocimiento, se basa principalmente en Educación e Investigación, Desarrollo e Innovación $(\mathrm{I}+\mathrm{D}+\mathrm{i})$. La sociedad ha evolucionado desde los recursos naturales, la industrialización y la prestación de servicios hasta una sociedad basada en la creación de conocimiento, uno de los pilares de este tránsito ha sido la Educación. La Educación permite formar el capital humano de calidad para la sociedad del conocimiento. Así, la Educación se ha transformado en un elemento clave para la realización personal y profesional en la sociedad basada en conocimiento. En la sociedad del conocimiento los profesionales aplican sus conocimientos formalmente adquiridos a través de su Educación, en este sentido la especialización profesional favorece la aplicación del conocimiento y el trabajo es más productivo, favoreciendo la creación de riqueza para el país.

Las instituciones universitarias juegan un rol clave para la sociedad del conocimiento, forman el capital humano requerido por esta sociedad y otorgan las posibilidades para adquirir una visión sistémica y la continua posesión del estado del arte que necesita éste. El capital humano en Ciencias de la Madera está siendo formado en diversas universidades de países europeos tales como Alemania, Bulgaria, Eslovaquia, Francia, Finlandia, Grecia, Portugal, Rumania, Rusia, Suecia, Turquía (Barbu 2013). En USA (Amstrong et al. 2014), así como también en algunas otras instituciones universitarias en el resto del mundo, tales como Argentina, Brasil, Canadá, Chile, China, Irán, México, Sudáfrica y Tailandia, entre otros (Tabla 1). 
Tabla 1. Algunas instituciones universitarias formando capital humano especializado en Ciencias de la Madera.

\begin{tabular}{|c|c|c|c|}
\hline País & Institución & Facultad/Dpto. & Sitio web \\
\hline Argentina & $\begin{array}{l}\text { Universidad } \\
\text { Nacional } \\
\text { Misiones }\end{array}$ & $\begin{array}{l}\text { Facultad de Ciencias } \\
\quad \text { Forestales }\end{array}$ & $\begin{array}{l}\text { http://www.facfor.unam.edu.ar/attachments/article/65/Ing\%20e } \\
\text { n\%20Ind\%20de\%20la\%20Madera\%202007.pdf }\end{array}$ \\
\hline Brasil & $\begin{array}{l}\text { Universidad } \\
\text { Federal Paraná }\end{array}$ & $\begin{array}{l}\text { Departamento de } \\
\text { Ciencias Forestales }\end{array}$ & www.madeira.ufpr.br \\
\hline Canadá & $\begin{array}{l}\text { University of } \\
\text { British } \\
\text { Columbia }\end{array}$ & $\begin{array}{l}\text { Department of } \\
\text { Wood Science }\end{array}$ & http://wood.ubc.ca/ \\
\hline Chile & UBB & $\begin{array}{l}\text { Departamento de } \\
\text { Ingeniería en } \\
\text { Maderas }\end{array}$ & http://dimad.ubiobio.cl/ \\
\hline China & $\begin{array}{l}\text { Nanging } \\
\text { Forestry } \\
\text { University }\end{array}$ & $\begin{array}{l}\text { College of Forest } \\
\text { Resources }\end{array}$ & http://eng.njfu.edu.cn/info.php?id=103 \\
\hline Irán & $\begin{array}{l}\text { University of } \\
\text { Tehran }\end{array}$ & $\begin{array}{l}\text { Department of } \\
\text { Wood and Paper } \\
\text { Science and } \\
\text { Technology }\end{array}$ & $\begin{array}{l}\text { http://www.ut.ac.ir/en/contents/Colleges- } \\
\text { Faculties/Agriculture/Natural- } \\
\text { Resources/Faculty.of.Natural.Resources.html }\end{array}$ \\
\hline México & $\begin{array}{l}\text { Universidad } \\
\text { Michoacana }\end{array}$ & $\begin{array}{l}\text { Facultad de } \\
\text { Ingeniería y } \\
\text { Tecnología de la } \\
\text { Madera }\end{array}$ & http://www.fitecma.umich.mx/facultad/typography.html \\
\hline Sudáfrica & $\begin{array}{l}\text { University of } \\
\text { Stellenbosch }\end{array}$ & $\begin{array}{l}\text { Department of } \\
\text { Forest and Wood } \\
\text { Science }\end{array}$ & $\begin{array}{l}\text { http://www.sun.ac.za/english/faculty/agri/departments1/forest- } \\
\text { and-wood-science }\end{array}$ \\
\hline Tailandia & $\begin{array}{l}\text { Kasetsart } \\
\text { University }\end{array}$ & $\begin{array}{l}\text { Department of } \\
\text { Forest Products }\end{array}$ & $\begin{array}{l}\text { http://www.ku.ac.th/web2012/index.php?c=adms\&m=selcon e } \\
\text { ng\&time }=20120806115238\end{array}$ \\
\hline USA & $\begin{array}{l}\text { University of } \\
\text { West Virginia }\end{array}$ & $\begin{array}{l}\text { Division of Forestry } \\
\text { and Natural } \\
\text { Resources }\end{array}$ & http://woodscience.wvu.edu/program overview \\
\hline
\end{tabular}

En Ciencias de la Madera, la resolución de problemas complejos de ingeniería requiere la participación no sólo del especialista, que sabe lo que hay que saber en Ciencias de la Madera, sino que también de otros profesionales con conocimiento especializado que dependen de la naturaleza del problema. Creo que en la sociedad del conocimiento la Educación especializada en Ciencias de la Madera se ha revalorizado y es una ventaja competitiva de cara a escenarios complejos, lo cual aparte de las competencias técnicas específicas de la especialidad (Amstrong et al. 2014, Rypstra 2011), requiere el desarrollo de las capacidades de trabajo en equipo, la comunicación, la visión sistémica y la continua posesión del estado del arte en Ciencias de la Madera.

\section{REFERENCIAS}

Amstrong, J.P.; Bustos, C.; Barnes, H.M. 2014. Education in wood science and technology: an update. Wood and Fiber Science 46(1):3-14.

Barbu, M.C. 2013. Changes in the European wood science education. Proligno 9(4):28-38.

Rypstra, T. 2011. Developments in undergraduate wood science education at Stellenbosch University, South Africa. Maderas Cienc Tecnol 13(1):117-125. 